\title{
MANAGEMENT OF EXTENSIVE DENTIGEROUS CYSTIC LESIONS IN ADULT PATIENT
}

\author{
Ehab Abdelfadil* and Samah I. Mourad**
}

\begin{abstract}
Background: The dentigerous cyst is the second most common developmental cysts of the jaws. Despite being asymptomatic in many cases, untreated lesions can reach significant sizes and result in extensive bone resorption. Associated complications may include facial asymmetry, teeth mobility, nerve compression, and pain. Large extensive dentigerous cyst are more difficult to manage.
\end{abstract}

Aim of the study: This study was conducted to evaluate the management of extensive dentigerous cysts in adults as well as the associated potential risks and complications.

Patients and methods: Fourteen (8 males and 6 females) patients with age range of 20-55 years (mean age of 33.9 years) who had large dentigerous cysts were included in this study. Enucleation of the cystic lesions along with the associated teeth was performed. Patients were clinically and radiographically evaluated for one year postoperatively.

Results: Nine mandibular (64.3\%) and 5 maxillary dentigerous cystic lesions $(35.7 \%)$ were operated. No surgical postoperative complications were encountered. Radiographic evaluation showed adequate new bone formation in the surgical defects within 6-12 months.

Conclusion: Untreated dentigerous cysts can reach a significant size. Extensive dentigerous cysts can be adequately treated with careful enucleation. Extensive dentigerous cysts may be associated with an increased risk for transformation into more aggressive lesions.

KEYWORDS: Dentigerous cyst, Extensive cyst, Adult, Surgical Enucleation.

\section{INTRODUCTION}

The dentigerous cyst is the second most common type of odontogenic cysts following the radicular cyst and represent approximately $20-24 \%$ among all jaw odontogenic cysts ${ }^{1-3}$. By definition, a dentigerous cyst develops around the crown of an unerupted tooth and is attached to the tooth cervix (enamel-cementum junction). The World Health Organization (WHO) classified dentigerous cysts as developmental odontogenic cysts ${ }^{4}$ that usually develop around an unerupted impacted

* Lecturer, Oral and Maxillofacial Surgery Department, Faculty of Dentistry, Mansoura University, Egypt.

** Associate Professor, Oral and Maxillofacial Surgery Department, Faculty of Dentistry, Mansoura University, Egypt. 
mandibular or maxillary third molar, maxillary canines, and mandibular second premolars ${ }^{4,5}$. They may also develop around supernumerary teeth and in association with odontomas; however, they are rarely associated with primary teeth. There is a slight male predilection and most dentigerous cysts usually are solitary. The bilateral or multiple involvement of this cyst is rather rare unless accompanied with an underlying systemic disease or a syndrome, such as Maroteaux-Lamy syndrome and cleidocranial dysplasia ${ }^{6,7}$.

Dentigerous cysts develop by accumulation of fluids in the follicular space between the reduced enamel epithelium and the crown of a developing or impacted tooth. When the fluid accumulates between the reduced enamel epithelium and the enamel or within the enamel organ itself the cyst is considered intra-follicular. Extra-follicular cysts are associated with foci of enamel hypoplasia within the crown of the involved tooth ${ }^{8}$. The highest incidence of dentigerous cysts is usually seen during the second and third decades of life. However, sometimes it may escape diagnosis until old ages owing to the asymptomatic nature. ${ }^{9,10}$ Many dentigerous cysts are small and asymptomatic and discovered only serendipitously on routine radiographs. Extensive lesions, on the other hand, grow to a considerable size and may result in complications including facial asymmetry, tooth movement, and neoplastic transformation ${ }^{11}$. Pain and numbness are usually encountered only if the cyst is secondarily infected ${ }^{7}$.

Radiographically, the dentigerous cyst is presented as a well-defined unilocular radiolucency, often with a sclerotic border, surrounding the crown of an unerupted tooth. A large dentigerous cyst may give the impression of a multilocular appearance because of the persistence of bone trabeculae within the radiolucency ${ }^{12}$. It is difficult to distinct radiographically between an enlarged dental follicle and a small dentigerous cyst. Thus, any pericoronal radiolucency that is larger than $3 \mathrm{~mm}$ is considered suggestive of cyst formation and should be submitted for microscopic examination ${ }^{12,5}$.
Enucleation with removal of the related tooth if necessary is one of the treatment options of dentigerous cysts ${ }^{7}$. Marsupialization is another treatment option that is frequently suggested for large cystic lesions or when the involved teeth are to be saved ${ }^{13,14}$. However, there is no solid guidelines for selecting the proper treatment option.

Surgical removal of extensive dentigerous cysts is associated with multiple potential risks including jaw fracture and injury of vital structures. This study was conducted to evaluate enucleation as a definitive treatment of large dentigerous cysts in adults.

\section{PATIENTS AND METHODS}

This study was conducted on 14 patients ( 8 males and 6 females) with age ranging from 20 to 55 years. Patients were selected from the outpatient clinic of the Oral and Maxillofacial Surgery Department, Faculty of Dentistry, Mansoura University. All patients had large cysts associated with unerupted teeth within the maxilla or mandible. The patient's details regarding age, gender, and chief complaints are shown in table 1. All patients were clinically examined thoroughly. Aspiration with a 16- or 18-gauge needle was done in all cases to exclude solid lesions. Aspiration was easily done because large cystic lesions usually have areas with no or very thin covering bone. Various amounts of strawcoloured fluid were aspirated in all the cases. A detailed medical history was obtained, and bleeding profile were conducted for all patients before the surgical procedure is undertaken.

All patients were radiographically examined using Panoramic (OPG) radiography and cone beam computed tomography (CBCT) to evaluate the size of the lesion and its proximity to anatomical vital structures (maxillary sinus or inferior alveolar neurovascular bundle). The exclusion criteria were: 1. Patients have systemic diseases contraindicating surgery, 2. Cases in suspicion of malignant transformation. When teeth other than wisdom teeth are involved, an orthodontist was consulted 
TABLE (1) Showing: patients' demographic data and lesions site, and clinical manifestations.

\begin{tabular}{|c|c|c|c|c|c|c|c|}
\hline $\begin{array}{l}\text { Patient } \\
\text { case No. }\end{array}$ & Age & Gender & Jaw & $\begin{array}{l}\text { Causative } \\
\text { tooth }\end{array}$ & site & Clinical manifestations & $\begin{array}{c}\text { Teeth } \\
\text { extracted }\end{array}$ \\
\hline 1 & 26 & Female & Mandible & LL8 & $\begin{array}{l}\text { LL7 and 8, } \\
\text { mandibular angle } \\
\text { and entire ramus }\end{array}$ & $\begin{array}{c}\text { Mobility type } 2 \text { of LL7 } \\
\text { Lingual bone expansion at } \\
\text { LL7 \& LL8 }\end{array}$ & LL8 \\
\hline 2 & 48 & Male & Mandible & LR 8 & $\begin{array}{l}\text { LR } 7 \text { to lower third } \\
\text { to ascending ramus }\end{array}$ & $\begin{array}{l}\text { Discover with routine X-ray } \\
\text { Asymptomatic }\end{array}$ & LR8 \\
\hline 3 & 55 & Female & Maxilla & Mesiodens & UR4 to UL5 & Palatal bone expansion & Mesiodens \\
\hline 4 & 47 & Female & Maxilla & Supernumerary & UR 1 to UR7 & $\begin{array}{l}\text { Buccal bone expansion } \\
\text { from UR1 to UR7 }\end{array}$ & $\begin{array}{c}\text { Supernumerary } \\
\text { tooth }\end{array}$ \\
\hline 5 & 20 & Male & Maxilla & supernumerary & UR 1 to UR 3 & $\begin{array}{l}\text { Mucosal inflammation } \\
\text { related to UL } 1 \text { to UL } 3\end{array}$ & $\begin{array}{c}\text { Supernumerary } \\
\text { tooth }\end{array}$ \\
\hline 6 & 33 & Male & Mandible & LL6 & LL5 to LL7 & $\begin{array}{c}\text { Numbness at LL jaw side } \\
\text { Secondary infection }\end{array}$ & LL $6 \& 7$ \\
\hline 7 & 35 & Female & Mandible & LL8 & $\begin{array}{l}\text { LL7 to half of } \\
\text { ascending ramus }\end{array}$ & $\begin{array}{c}\text { Buccal bone expansion at } \\
\text { UL8 }\end{array}$ & UL7 \&UL8 \\
\hline 8 & 23 & Male & Mandible & LR3 & LR2 to LR4 & $\begin{array}{c}\text { Absence of LR3 } \\
\text { Mobility grade } 2 \text { at LR2 }\end{array}$ & LR3 \\
\hline 9 & 25 & Male & Mandible & LR8 & $\begin{array}{l}\text { LR8 to Lower third } \\
\text { of ascending ramus }\end{array}$ & $\begin{array}{c}\text { Buccal bone expansion at } \\
\text { LR8 }\end{array}$ & LR8 \\
\hline 10 & 44 & Male & Maxilla & UR8 & UR7 to UR8 & Mobility grade 2 of UR7 & UR7 \&UR8 \\
\hline 11 & 24 & Female & Maxilla & UR3 & UL2 to UR4 & Buccal bone expansion & UR3 \\
\hline 12 & 22 & Male & Mandible & LL8 & LL8 & $\begin{array}{c}\text { Asymptomatic, discover } \\
\text { accidentally in routine x-ray } \\
\text { examination }\end{array}$ & LL8 \\
\hline 13 & 38 & Male & Mandible & UL8 & UL6 to UL8 & Mobility grade 2 at UL7 & UL8 \\
\hline 14 & 32 & Female & Mandible & LL3 & LL3 & Absence of LL3 & LL3 \\
\hline
\end{tabular}

LL: Lower Left, LR: Lower Right,UR: Upper Right, UL: Upper Left.

to determine whether the teeth could be saved and brought into proper position using orthodontic treatment. This study followed the Declaration of Helsinki on medical protocol and all participants signed an informed consent form.

\section{Surgical procedures}

With compliance to aseptic surgical protocol, all patients were treated under local anaesthesia using
Mepicaine-L (Mepivacaine HCL 2\% 1-20.000 (Manufacture by Alexandria Co. for pharmaceuticalAlexandria- Egypt). A full thickness mucoperiosteal flap was elevated to provide an adequate access to the surgical area. Using rotatory round and fissure burs with adequate cooling system, the cyst cavity was assessed if a thick covering bone is encountered. Complete enucleation of the cyst lining using bone curette was performed with extraction of 
the causative tooth Table 1. Following bleeding control and wound inspection and debridement, surgical wounds were closed primarily with nonresorbable black silk suture (3.0). All specimens were sent for confirmation of the final diagnosis by histopathological examination.

\section{Follow-up}

All patients were given verbal and written postoperative instructions to ensure proper wound hygiene and postoperative care. Antibiotic therapy comprised of Amoxycillin + Clavulanate Potassium (Augmentin, Medical Union Pharmaceuticals. Cairo, Egypt) 1gm every 12 hours orally, starting 60 minutes before intervention, and continued for 5days during the post-operative period was prescribed. In addition, an antiedematous, anti-inflammatory agent Alphintern (Chymotrypsin 300 E.A.U, Amoun pharmaceutical Co., S.A.E) was administered 3 times daily for 5 days. Also, nonsteroidal anti-inflammatory drugs Ibuprofen 600 (BRUFEN, khirapharm. and Chem. Ind. Co. Cairo-Egypt) three times per day was prescribed for pain control. Additionally, antiseptic chlorhexidine mouth wash (Oraldene, Hikma Pharma S.A.E. 6th of October City - Egypt) was used for 7 days after surgery to diminish the bacterial local load and to avoid any possible postoperative infection.

All cases were recalled one week after surgery for wound inspection and sutures removal. Two weeks later, patients were recalled again to assure wound condition. The patients were assessed radiologically every three months with panoramic radiographs during follow-up period. All cases were followed for at least one year, depending on clinical examination.

\section{RESULTS}

Fourteen patients were enrolled in this study. There were 8 males (57.1\%) and 6 females (42.9\%) with a 4:3 Male to Female ratio. Patients age ranged from 20 to 55 years with a mean age of $33.9 \pm 11.1$ years. The peak incidence age was at the third decade of life (Fig. 1). The operated cysts included 9 mandibular lesions (64.3\%) and 5 maxillary lesions $(35.7 \%)$. The common clinical manifestation of cases was bone expansion (swelling) (6 patients), teeth mobility (4 patients), failure of tooth eruption (2 patients), and only one case complaint of numbness that occurred secondary to infection and was completely resolved after initial management of the infection.

Radiographically, all cystic lesions were seen as large unilocular well defined, corticated radiolucencies. The associated teeth were displaced and partially or completely enclosed within the lesion. Cortical expansion with or without perforation was frequently noted. Half of the present study lesions were associated with impacted third molars $(50 \%)$ Fig. $(2,3)$ while 3 cases (21\%) were related to impacted canines, and four (29\%) with other teeth that compromised of one mesiodens case Fig. (4), two supernumerary tooth cases Fig. $(5,6)$, and only one case related to mandibular first molar Fig (7). The lesions-related teeth association is shown in figure (8).

Patients' age and gender as well as the cyst location, causative tooth, involved teeth and clinical manifestation are shown in Table (1).

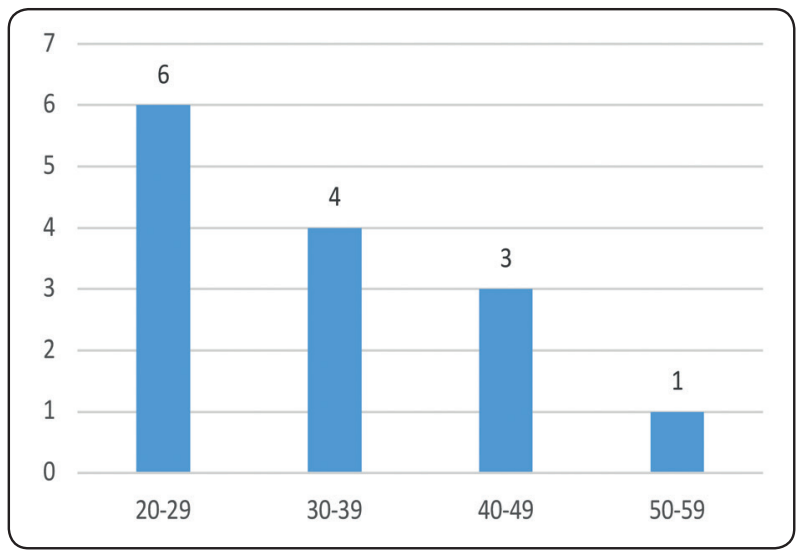

Fig. (1) Prevelance of dentigerous cyst according to age 


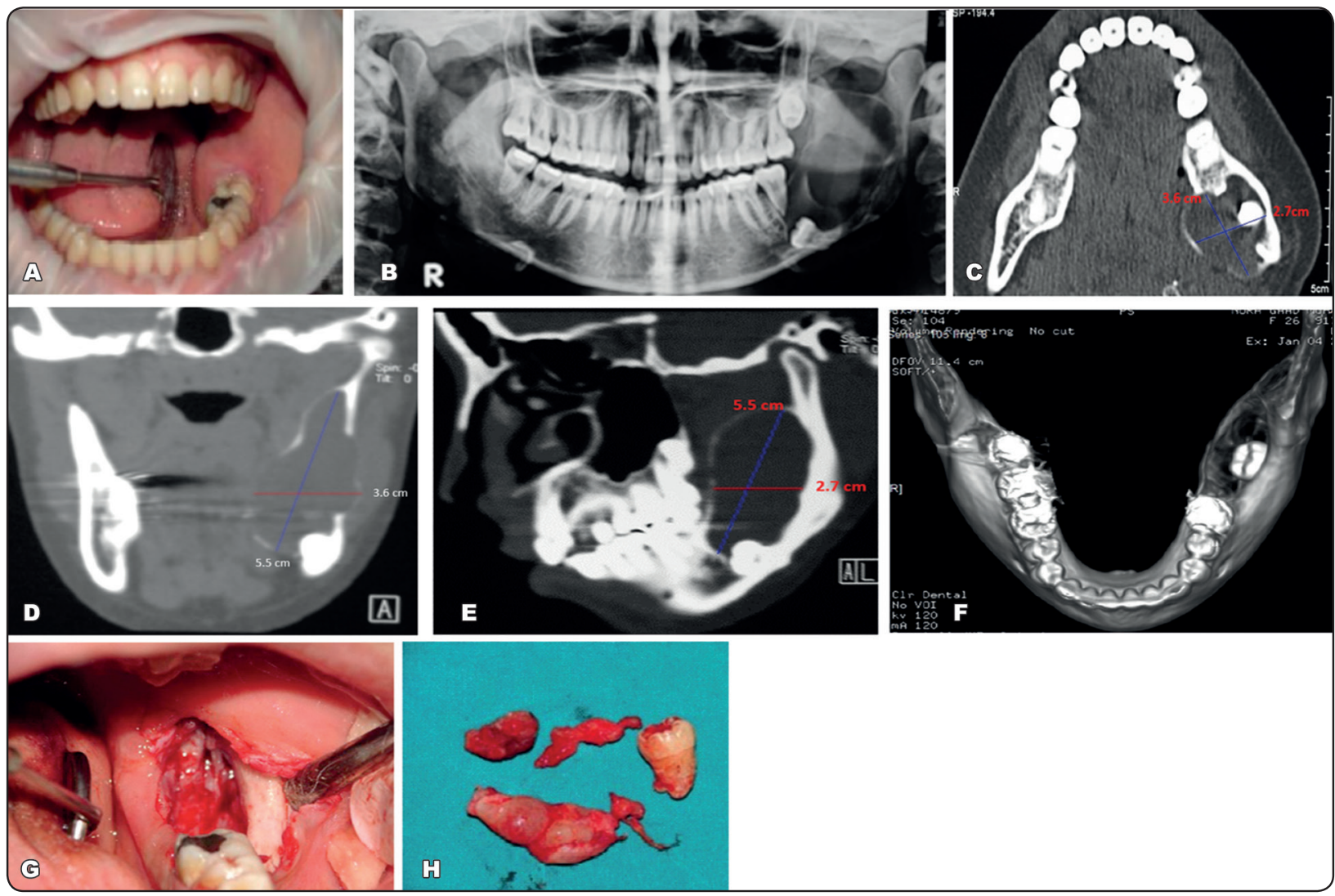

Fig. (2) Dentigerous cyst associated with impacted lower left third molar (Case 1). a) Intraoral clinical photograph showing expansion of lingual plate of bone. b) Perioperative Panoramic radiograph showing displaced lower left third molar with large unilocular radiolucency extending to ascending ramus. (c, d, e, f) Axial, coronal, Sagittal and 3 dimensions (3.D) sections of the dentigerous cyst $(5.5 \times 3.6 \times 2.7 \mathrm{~cm}) \mathrm{g}$. Intraoperative clinical radiograph showed the bony defect after enucleation of cyst lining. h. Photograph showing the excised dentigerous cyst together with the extracted impacted tooth.

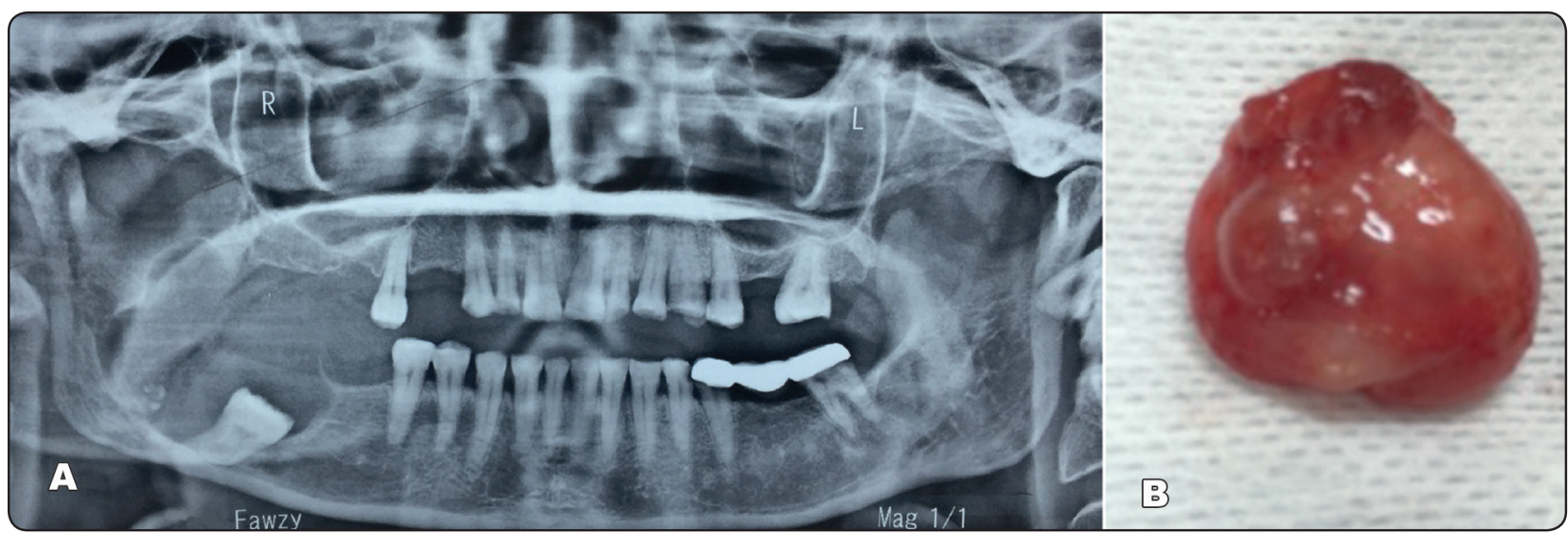

Fig. (3) Dentigerous cyst associated with impacted lower Right third molar (case 2). a) Perioperative Panoramic radiograph showing displaced lower right third molar with large unilocular radiolucency extending to ascending ramus. b) Photograph showing the enucleated dentigerous cyst. 
The surgical procedures were well tolerated by all patients. No postoperative complications were encountered.

Histopathological confirmation of dentigerous cyst was obtained in 11 cases $(79 \%)$ that revealed lining formed of squamous epithelium overlie oedematous \& dense C.T. with no inflammatory cells. While 2 cases (14\%) confirmed an inflammatory dentigerous cyst in which the cyst lining showed diffuse chronic inflammatory cells infiltration to the fibrous connective tissue stroma. Strands of ameloblastoma forming of peripheral columns epithelial cells and central stellate reticulum cells that microscopically confirmed the ameloblastic transformation in the dentigerous cyst wall (mural ameloblastoma) in only one case of the present study cases. The patient was informed of the histopathological results, the nature of the lesion aggressiveness, and prognosis. Regular and meticulous clinical and radiological follow-up was performed with no recurrence detection.
Complete resolution of the cystic lesion with normal intraoral wound healing was achieved with no signs of infection or recurrence. Radiographic examination showed spontaneous newly formed bony trabeculation at all the surgical defects within 6-12 months from the surgical enucleation Fig. $(9 \& 10)$.

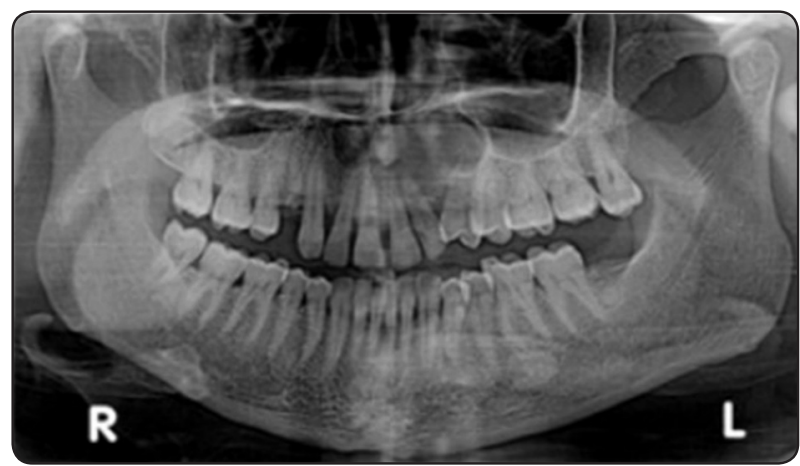

Fig. (4) perioperative panoramic radiograph showing Dentigerous cyst associated with a mesiodens (case3).

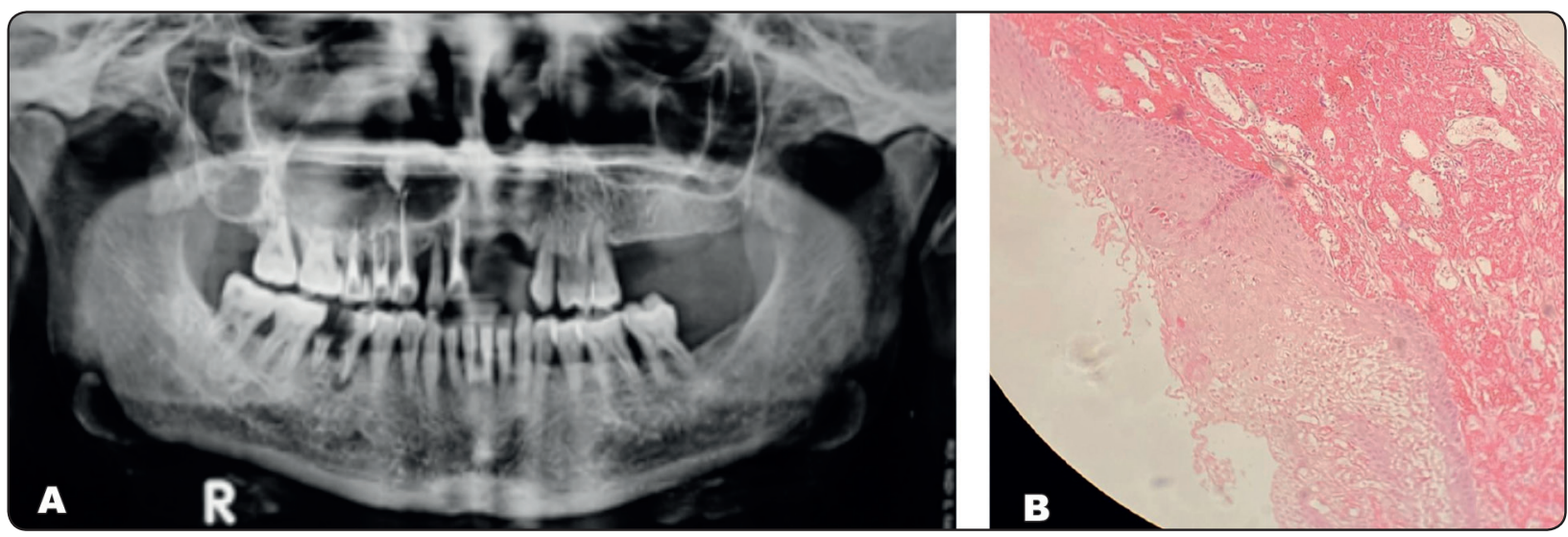

Fig. (5) Dentigerous cyst associated with supernumerary tooth (case 4). a) Perioperative panoramic radiograph showing large unilocular radiolucency associated with supernumerary tooth extending from the upper right central incisor to upper right. b) Histopathological examination (H\& E) revealed lining formed of squamous epithelium overlie oedematous and dense connective tissue with no inflammatory cells. 


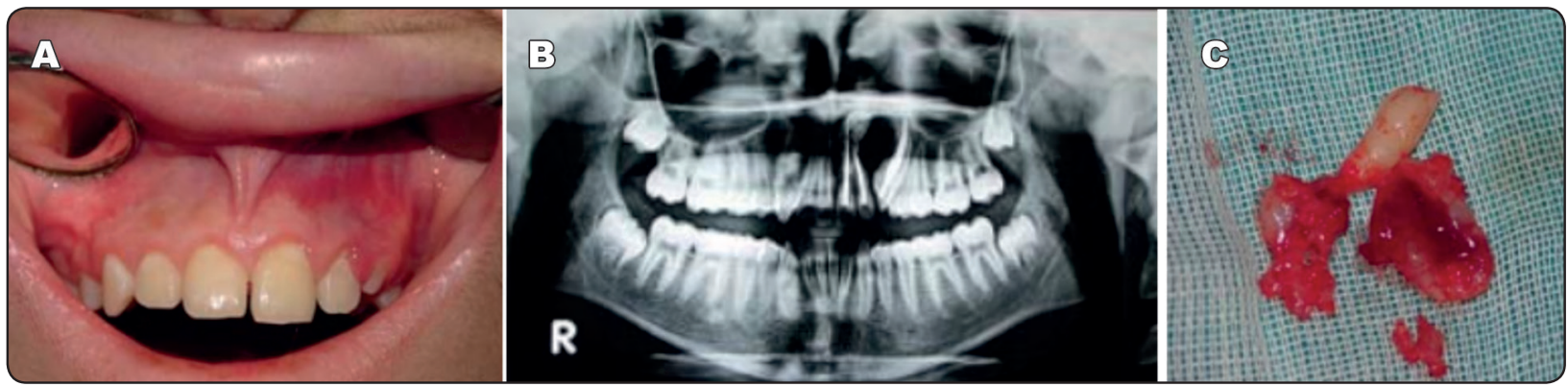

Fig. (6) Dentigerous cyst associated with supernumerary tooth (case 5). a). Intraoral clinical photograph showing mucosal inflammation at upper left anterior teeth area. b). Perioperative panoramic radiograph showing Dentigerous cyst associated with supernumerary tooth extending at upper left anterior teeth. c). Clinical photograph showing the excised dentigerous cyst together with the extracted supernumerary tooth.
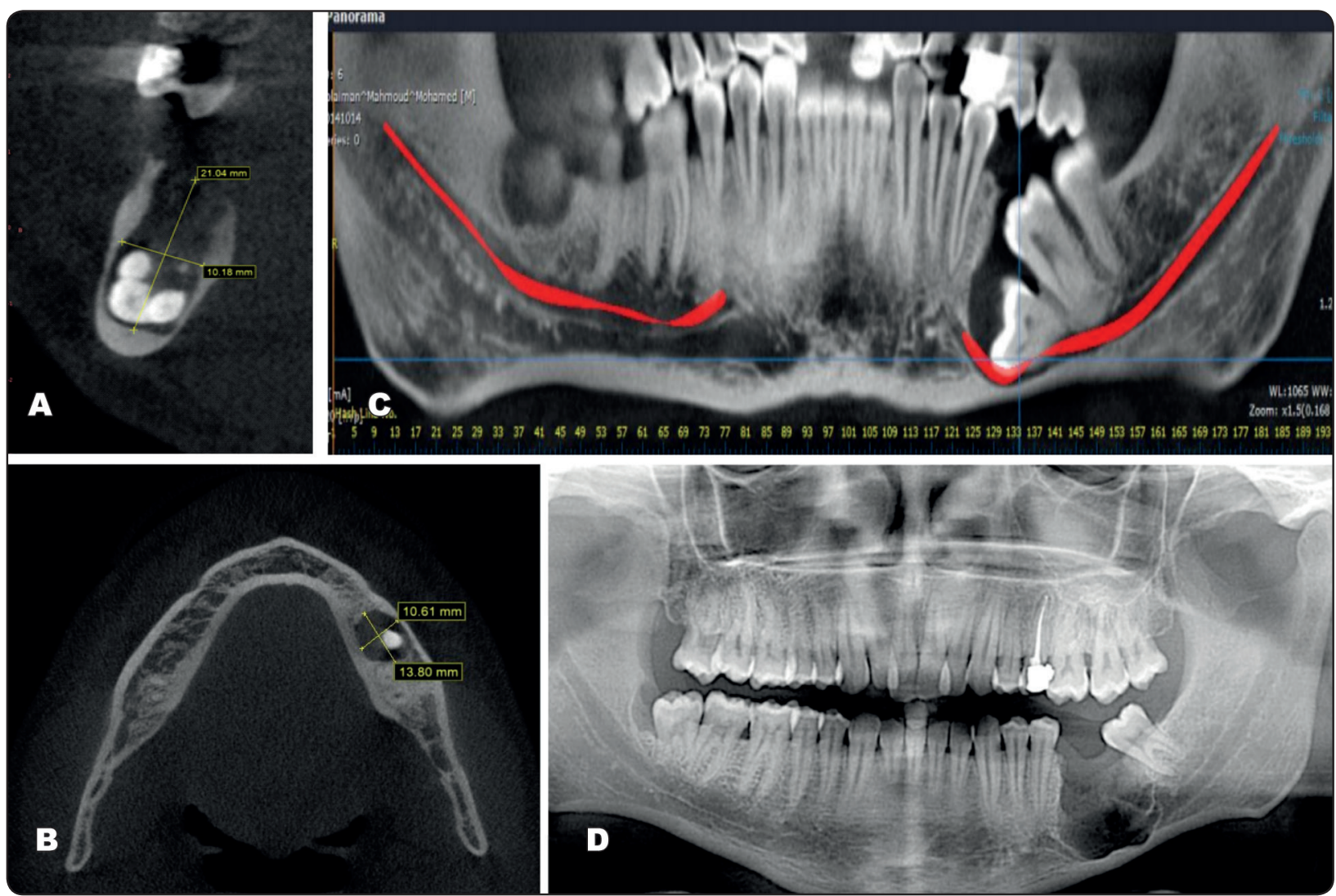

Fig. (7) Dentigerous cyst associated with mandibular left first molar (case 6- others). A, b) Coronal \&Axial CBCT sections of dentigerous cyst $(21.04 \times 13.8 \times 10.6 \mathrm{~mm})$ c) Perioperative panoramic radiograph showing dentigerous cyst associated with mandibular left first molar with compression of the inferior alveolar nerve. d) Immediate postoperative panoramic radiograph. 


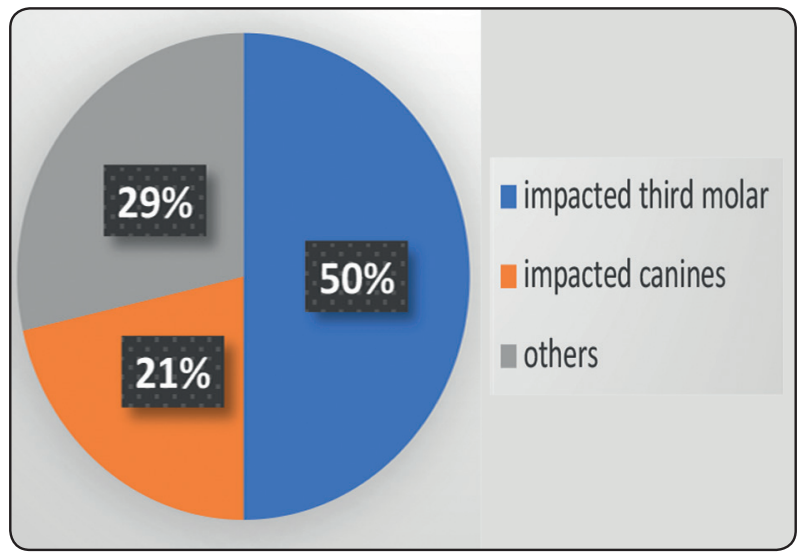

Fig. (8) Teeth associated with the dentigerous cyst lesions
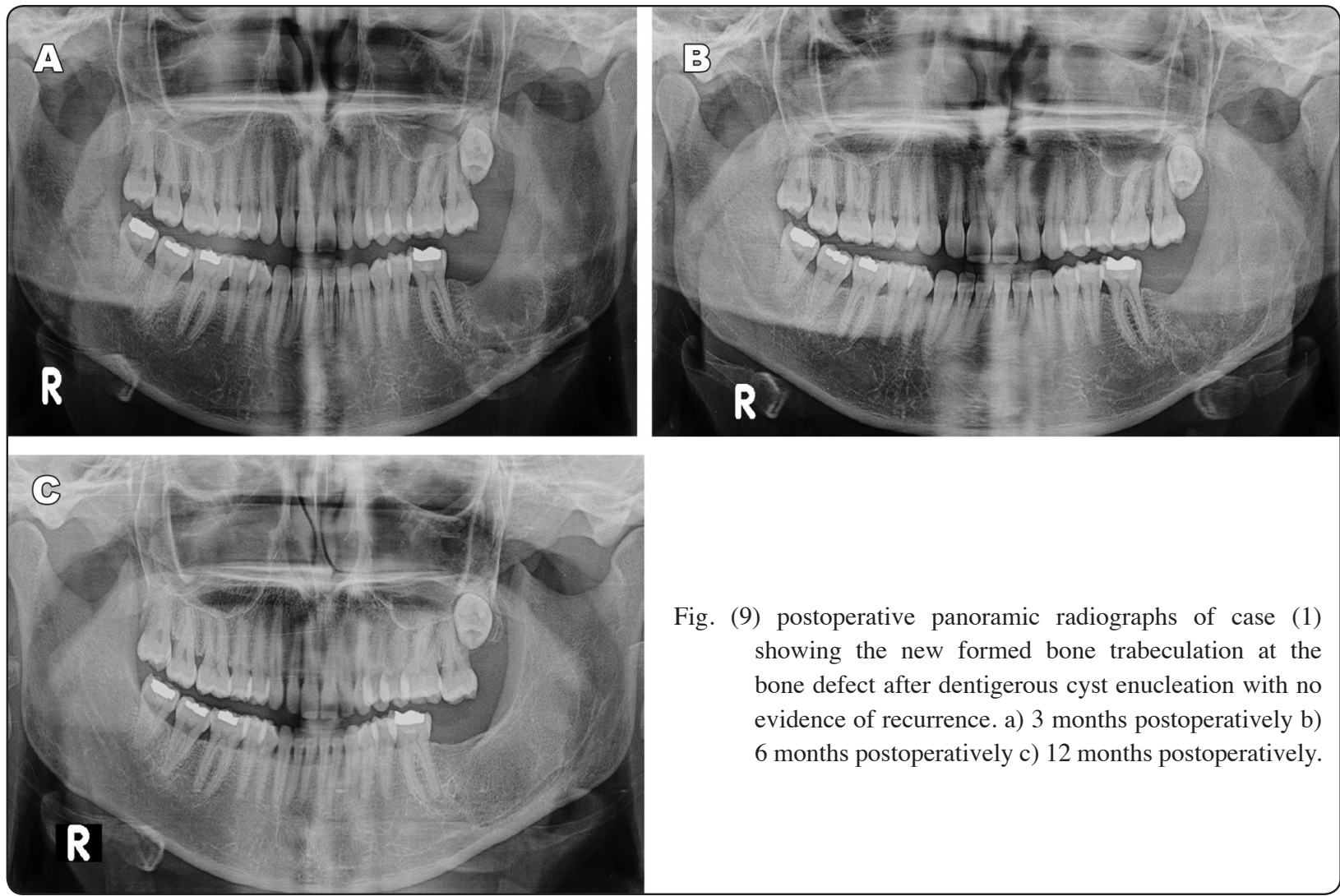

Fig. (9) postoperative panoramic radiographs of case (1) showing the new formed bone trabeculation at the bone defect after dentigerous cyst enucleation with no evidence of recurrence. a) 3 months postoperatively b) 6 months postoperatively c) 12 months postoperatively. 


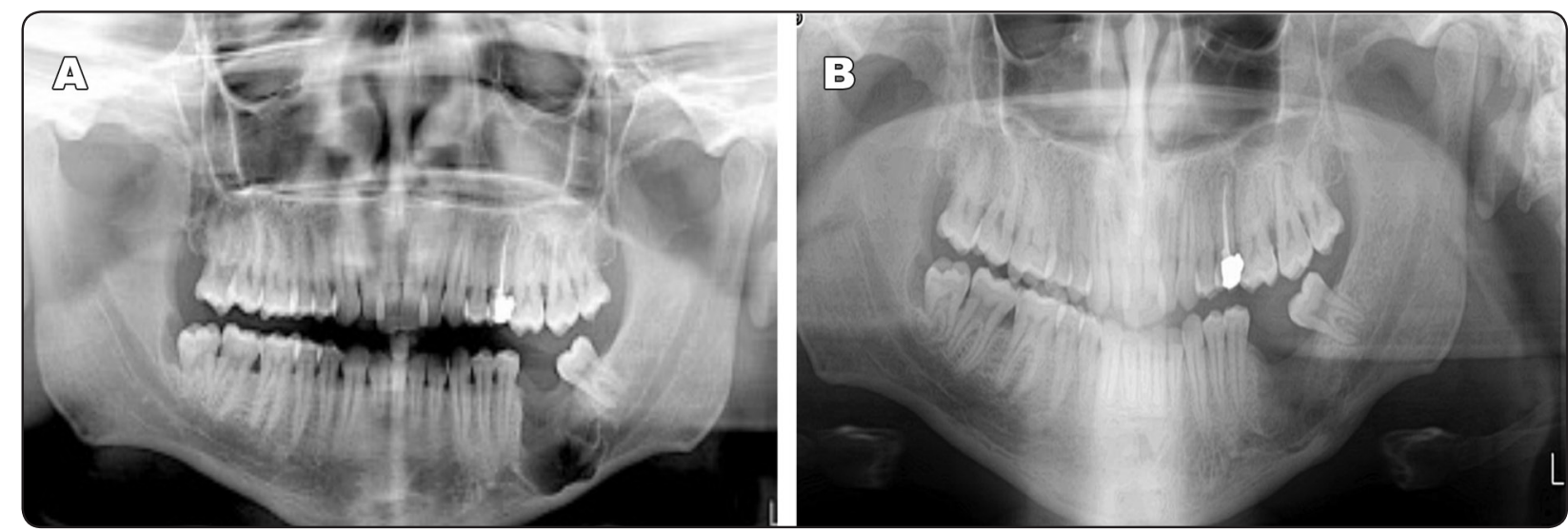

\section{DISCUSSION}

The dentigerous cyst was first described in the literature in France in 1778, and the first case report was published in 1842 by Harris C.A ${ }^{5,14}$. Considering the unfavourable damaging sequelae of untreated dentigerous cysts, surgery is always indicated. Described treatment modalities include decompression, marsupialization, and enucleation 15-19. There are no definite guidelines regarding which treatment is to be used. Selection is always made based on the operator preference with a general consensus that enucleation is the treatment of choice for small lesions, while marsupialization is indicated in case of large cysts.

In agreement with several studies ${ }^{10,15,20-22}$, most of the patients included in this study were in the third decade of life. Most of the lesions were associated with third molars, with the mandible more affected than the maxilla.

Although dentigerous cysts are described as developmental cysts, the etiological mechanism remains unknown. Shaw et.al (1980) was the first to introduce the term "inflammatory dentigerous cysts" ${ }^{\prime}$. Benn and Altini ${ }^{23}$ (1996) described inflammation as etiological factor for the development of dentigerous cysts. Inflammation arising from pulpally involved primary teeth is proposed to act as a stimulating factor that results in accumulation of fluid between the reduced enamel epithelium and the crown of the unerupted tooth ${ }^{24}$. Despite this theory may explain the cases where the cyst is related to a tooth that has a predecessor, it is unlikely to be a solid explanation of cysts related to third molar teeth, since cyst can form around completely bony impacted teeth. The histopathological features of inflammatory dentigerous cysts are characterized by presence of diffuse chronic inflammatory cells within the cyst lining and at the odontogenic epithelium forming small groups within the cyst wall ${ }^{15}$. The exact presentation was encountered in two of the cases involved in this study. However, inflammation is probably originated from the surrounding tissue and/or teeth and not the cause of cyst formation.

Despite being a benign lesion, neoplastic transformation in the dentigerous cyst lining if left untreated has been reported in the literature that include ameloblastoma ${ }^{16,17,19}$, Squamous cell carcinoma, and intraosseous mucoepidermoid 
carcinomas $^{3,10,15}$. However, the malignant transformation was extremely rare with rate ranged $0.13 \%$ and $3 \%$ 5,25. Considering the results of the current study, one case was confirmed with transformation to ameloblastoma with no recurrence detection along one year follow-up period.

Dentigerous cysts are usually asymptomatic. However, as they reach a significant size, multiple signs and symptoms could be evident. In the present study, intraoral or extraoral swelling, tooth mobility, and displacement of adjacent tooth were mainly observed, which is in agreement with Nagaraj et.al (2017), who reported a dentigerous cyst of inflammatory origin in mixed dentition ${ }^{26}$. Multiple theories were described to explain the expansion of dentigerous cysts that could expanded from the wisdom tooth superiorly to the ramus or along the mandibular body in inferior direction asymptomatic unless secondary infection occurred ${ }^{27}$. The increased osmolarity of the cyst fluid increases the internal hydrostatic pressure of the cyst. Arendorg et.al., (1981) suggested prostaglandins role. He stated that PGE2 and PGE3 which are released from the dental follicle may resorb cementum and dentine which in turn causes expansion of the cyst ${ }^{15}$. Meghji, Harvey, and Harris in 1989 stated that the monocyte-macrophage infiltrate along with the stromal fibroblasts' releases interleukin-1 which causes several osteolytic cell reactions, stimulating osteoclasts and resorption of bone stimulating connective tissue cells which in turn causes the production of collagenase that leads to the destruction of the bone matrix ${ }^{28}$.

The radiographic picture of dentigerous cyst is not pathognomonic. Other lesions that can exhibit similar presentation such as radicular cyst, odontogenic keratocyst, unicystic ameloblastoma, Pindborg tumour, odontoma, and cementoma ${ }^{10}$. An enlarged dentigerous cyst will push the tooth away from its direction of eruption to the ramus or inferior border (mandibular molars) or to the sinus or nasal floor (maxillary molars and cuspids) ${ }^{29}$. Hyeok et. al., (2014) found that downward, backward, and upward directions are the most common directions of tooth displacement rather than the mesiodistal direction. Cortical bone expansion, loss of bony continuity, and root resorption are less common radiological features of enlarged dentigerous cysts. However, in our study, one case was presented with complete loss of some areas of the medial and lateral surfaces of the mandibular ramus. Moreover, attention should be paid to differentiate between small dentigerous cyst and dental follicle with considerable size ${ }^{30}$.

Although panoramic radiograph is the most commonly used modality for screening and tentative diagnosis, it produced only two-dimensional image of intraosseous lesions and oral structures. Panoramic radiographs are reported to be sufficient with respect to small unilocular radiolucent dentigerous cysts with sclerotic margins that surround the crowns of unerupted teeth ${ }^{30,31}$. CBCT, on the other hand, provides a three-dimensional picture that accurately reveal the proximity of the lesion to adjacent vital structures such as the nasal floor, maxillary sins, and the inferior alveolar canal ${ }^{32}$. When dealing with large dentigerous cysts, CBCT is indispensable for planning of the surgical procedure. It should be borne in mind that radiographic findings are not enough for definite diagnosis of dentigerous cysts. Microscopic examination is still mandatory to confirm diagnosis ${ }^{10}$.

Surgical removal is the treatment choice of dentigerous cysts. However, there is always a concern about the involved teeth especially if the lesion is related to a functional tooth. The surgical protocol is determined after careful evaluation of the size and extent of the cyst, the tooth involved, the surgical access, and the potential risks including injury to vital structures and jaw fracture ${ }^{33}$. Pathological jaw fractures related to odontogenic cysts are very uncommon. Only 12 cases were 
reported in literature, including a single case that involved a dentigerous cyst. Eleven of the reported pathological fractures involved the mandible, with a higher incidence in men ${ }^{34}$.

Marsupialization is a conservative, less aggressive technique compared to enucleation, that is commonly utilized in children to preserve the involved permanent teeth. A second surgical procedure is needed for complete removal of the cyst lining. However, there is always a concern regarding the histopathological nature and the risk of transformation for the tissue part left in situ after marsupialisation ${ }^{35,36}$. Tainie et.al., (2020) described a two stages protocol, consisting of a marsupialization followed by an enucleation at a later stage. The rationale behind this protocol is to decrease the lesion size and hence minimize the risk of damaging vital structures. However, this technique necessitates a highly cooperative patient that can achieve adequate oral hygiene and be committed to long- term follow up to achieve success ${ }^{37}$.

In our present study, enucleation with extraction of the involved teeth was always the treatment of choice as it involves removal of the entire pathological tissues and at the same time eliminate the need of multiple follow up visits that necessitate substantial patient compliance. Enucleation also eliminates the risks associated with leaving a pathological tissue in situ ${ }^{14,38}$. In our opinion, considering the benign nature of cystic lesions which tend to displace the vital structures rather than incorporating them within the lesion, injury of vital structures is extremely unlikely if the surgery is performed by an experienced surgeon after careful planning using CBCT. Additionally, Specific criteria were assessed to determine whether the risk of fracture was significant after thorough evaluation of the preoperative radiographs. These criteria were (1) The need for significant bone removal to gain access to the lesion. (2) The thickness of the inferior border of the mandible. (3) Extent of cortical resorption. (4) The bone support around the involved tooth and the tooth/teeth to be removed. The lesions involved in this study were large enough to cause expansion with the extensive loss of cortical buccal bone which facilitated gaining access to the lesion without the need of excessive bone, which minimized the possibility of jaw fracture.

Extraction of the associated teeth other than the causative one was decided depending on the extent tooth displacement, bone loss, tooth mobility and inadequate bone volume in the residual cavity that jeopardise the tooth vitality ${ }^{24}$. Cyst enucleation with removal of associated teeth was also recommended by Aggarwal et. al. (2011) and Moosvi et.al., (2011) 39,40 . They recommended this approach in case of large size, displacement of teeth and destruction of cortical bone. Besides, this treatment is curative and allow complete bone formation without recurrence ${ }^{10}$. The financial shortage and lack of dental health insurance impacted the use of CBCT for postoperative bone healing evaluation, that was considered a limitation point of the present study.

\section{CONCLUSION AND RECOMMENDATIONS:}

- Enucleation is a successful and recommended approach for large dentigerous cysts.

- Negligence of investigation of delayed eruption of teeth can result in extensive dentigerous cyst lesions.

- Transformation of dentigerous cysts into aggressive lesions is a potential risk associated with large dentigerous cysts.

- Histopathological examination of dentigerous cysts is essential for definitive diagnosis.

- Preoperative CBCT is essential for evaluation of large dentigerous cysts and for proper formulation of the surgical protocol to decrease morbidity. 


\section{REFERENCES}

1. Soames JV, Southam JC. (1993): Oral Pathology, p. 74, Oxford 2nd ed.; Oxford University Press.

2. Ko KS, Dover DG, Jordan RC. (1999): Bilateral dentigerous cysts: report of an unusual case and review of the literature. J Can Dent Assoc., 65:49-45.

3. Tamgadge A, Tamgadge S, Bhatt D, Bhalera, S, Pereira T, Padhye M. (2011): Bilateral dentigerous cyst in a nonsyndromic patient: report of an unusual case with review of the literature. J Oral and Maxillofac Pathol., 15:91-95.

4. Nunez-Urrutia S, Figueiredo R, Gay-Escoda C. (2010): Retrospective clinicopathological study of 418 odontogenic cysts. Med Oral Patol Oral Cir Bucal., 5:e767-773

5. Hajj R, Dagher J, Nasseh I.(2019): Infrequent radiological features of a dentigerous cyst-A case report. Int Dent Med J Adv Res., 5:1-4.

6. Ustuner, E, Fitoz S, Atasoy C, Erden I, Akyar, S. (2003): Bilateral maxillary dentigerous cysts: a case report. Oral Surg Oral Med Oral Pathol Oral Radiol Endod., 95:632-635.

7. Yaman D, Akay G , Güngör K. (2020): Multiple dentigerous cysts with radiological findings in a non-syndromic patient. J Dent Fac Atatürk Uni., 30:122-125.

8. Sarvesh Vijay, Yogesh T.L, Dr.Anjani K Jha, Nonitha.S. (2019): Keratinizing Dentigerous Cyst - An Unusual EntityA Rare Case Report Int. J. Drug Res. Dental Sci., 1: 6-10.

9. Demirtaş N, Mihmanli A, Bayer S, Özalp Ş. (2016): Dentigerous cysts in the mixed dentition: report of three cases. J Dent Fac Atatürk Uni., 14:23-26.

10. Wadde K, Alam N, Chapane A. (2019): Dentigerous cyst of the jaws: A case series. J Oral Med, Oral Surg, Oral Pathol, Oral Radiol., 5(1):14-17

11. José MV, Jorge AE, Yamile EG. (2016): Dentigerous cysts: Case report. J Adv Oral Res., 3:527-534

12. Miloro M, Ghali GE, Larsen P, Waite P. (2004): Peterson's principles of oral and maxillofacial surgery, p 576, (2nd ed), vol (1), Hamilton, BC Decker Inc.

13. Devi P, Thimmarasa VB, Mehrotra V, Agarwal M. (2015): Multiple dentigerous cysts: a case report and review. J Maxillofac Oral Surg ., 14:47-51.

14. Regezi J, Sciubba J, Jordan R. (2008): Oral pathology: Clinical pathologic correlations, p246, 5th ed. Philadelphia; Saunders Company.
15. Vijay S, Yogesh T L, \& Jha A, Nonitha S. (2019): Keratinizing Dentigerous Cyst - An Unusual Entity-A Rare Case Report. Int J Drug Res \& Dent Sci., 1: 6-10.

16. Assael L A. (1992): Surgical management of odontogenic cysts and tumors. Vol 2, P685-688, Peterson L J, Indresano T A, Marciani R D, Roser S M. Principles of Oral and Maxillofacial Surgery. Philadelphia: JB Lippincott.

17. Neville B W. (1995): Odontogenic cysts and tumors, p 493, Neville B W, Damm D D, Allen C M, Bouquot J E. Oral and Maxillofacial Pathology. Philadelphia: WB Saunders.

18. Regezi J A.(2000): Cyst and cystlike lesions. P 88, Regezi J A, Sciubba J, Pogrel M A. Atlas of Oral and Maxillofacial Pahtology. Philadelphia: WB Saunders.

19. Martínez-Pérez D, Varela-Morales M. (2001): Conservative treatment of dentigerous cysts in children: report of four cases. J Oral Maxillofac Surg., 59: 331-334.

20. Khambete N, Kumar R, Risbud M, Kale L, Sodhi S. (2012): Dentigerous cyst associated with an impacted mesiodens: report of 2 cases. Imaging Sci Dent., 42:255-260.

21. Reyes JMV, Bermúdez JAE, Ruisánchez YEG. (2016): Dentigerous cysts: Case report. J Adv Oral Res., 7:41-45

22. Jain N, Gaur G, Chaturvedy V, Verma A. (2018): Dentigerous cyst associated with impacted maxillary premolar: a rare site occurrence and a rare coincidence. Int $\mathrm{J}$ Clin Pediatr Dent., 11:50-52

23. Benn A, Altini M. (1996): Dentigerous cysts of inflammatory origin: A clinicopathologic study. Oral Surg Oral Med Oral Pathol Oral Radiol Endod., 81: 203-209

24. Jayam C, Mitra M, Bandlapalli A, Jana B. (2014). Aggressive dentigerous cyst with ectopic central incisor. BMJ Case Rep., 9: bcr2013201041.

25. Pant B, Carvalho K, Dhupar A, Spadigam A. (2019): Bilateral non- syndromic dentigerous cyst in a 10-year-old child: A case report and literature review. Int J Appl Basic Med Res., 9: 58-961

26. Nagaraj T, Irugu K, Balraj L, Bhavana TV. (2017): Dentigerous cyst of inflammatory origin in mixed dentition: A case report and review of literature. Int J Med Dentistry Case Reports., 4:1-5.

27. Yavuz F, Timucin B. (2012): Huge mandibular dentigerous cyst treated under local anesthesia. Int J Exp Dent Sci.,1:45-47.

28. Jeyaraj p, Mohan SM. (2008): Dentigerous cyst of the mandible with multiple complex odontomas. Med J Armed Forces India.,64:382-383. 
29. Salazar M, Séllos MC, Americano GCA, da Costa MP, de Marsillac MWS, Campos V. (2017): Dentigerous Cyst Involving Permanent Incisor: A Case Report. SM J Dent., 3(2): 1014s.-1017s

30. Lee JH, Kim SM, Kim HJ, Jeon KJ, Park KH, Huh JK. (2014): Characteristics of bony changes and tooth displacement in the mandibular cystic lesion involving the impacted third molar. J Korean Assoc Oral Maxillofac Surg., 40:225-232.

31. Evie S, Sandhya T, Avinash T, Sudhir B. (2016): Histopathological and radiographic analysis of dental follicle of impacted teeth using modified Gallego's stain. J Clin Diagn Res.,10:106-111.

32. Borrás-Ferreres J, Sánchez-Torres A, Gay-Escoda C. (2016): Malignant changes developing from odontogenic cysts: A systematic review. J Clin Exp Dent., 8:622-628

33. Kirtaniya BC, Sachdev V, Singla A, Sharma AK. (2010): Marsupialization: A conservative approach for treating dentigerous cyst in children in the mixed dentition. J Indian Soc Pedod Prevent Dent., 28:203-208.

34. Kouhsoltani M, Mesgarzadeh AH, Moradzadeh Khiavi M. (2015): Mandibular fracture associated with a dentigerous cyst: report of a case and literature review. J Dent Res Dent Clin Dent Prospects., 9:193-198.

35. Woods M, Reichart PA. (2017): Maxillofacial Surgery. 3rd ed. London, United Kingdom: Churchill Livingstone; p. 1319-1334.

36. Sarac Z, Peric B, Filipovic-Zore I, Cabov T, Biocić J. (2010): Follicular jaw cysts. Coll Antropol., 34 Suppl: 215-219.

37. De Moraes AT, Soares HA, Pinheiro JJ, Ribeiro AL. (2020): Marsupialization before enucleation as a treatment strategy for a large calcifying odontogenic cyst: Case report. Int J Surg Case Rep., 67:239-424.

38. Deboni MC, Brozoski MA, Traina AA, Acay RR, NaclérioHomem MG. (2012): Surgical management of dentigerous cyst and keratocystic odontogenic tumor in children: A conservative approach and 7-year follow-up. J Appl Oral Sci., 20:282-285.

39. Aggarwal P, Saxena S. (2011): Aggressive growth and neoplastic potential of dentigerous cysts with particular reference to central mucoepidermoid carcinoma. Br J Oral Maxillofac Surg., 49:36-39.

40. Moosvi Z, Tayaar SA, Kumar GS. (2011): Neoplastic potential of odontogenic cysts. Contemp Clin Dent., 2:106-109. 